\title{
DANOS DE Cornitermes cumulans Kollar, 1832 (ISOPTERA: TERMITIDAE) EM MUDAS DE Eucalyptus grandis $\mathbf{x}$ Eucalyptus urophylla
}

\author{
Patrícia da Silva Leitão-Lima ${ }^{1}$, Carlos Frederico Wilcken ${ }^{2}$, Eduardo do Valle Lima ${ }^{1}$ \\ ${ }^{1}$ Universidade Federal Rural da Amazônia, Campus de Capanema (UFRA/Capanema), Rua João Pessoa, n 121 , Bairro: Centro, \\ CEP: 68700-030, Capanema - PA. E-mail: patleitao@yahoo.com.br / eduardo.valle_lima@yahoo.com.br \\ ${ }^{2}$ Faculdade de Ciências Agronômicas - FCA/UNESP, Campus de Botucatu, Departamento de Produção Vegetal, Setor de Defesa \\ Fitossanitária, CEP: 18603-970, Botucatu - SP. E-mail: wilcken@ fca.unesp.br
}

\section{RESUMO}

O objetivo do trabalho foi avaliar o dano de Cornitermes cumulans a estruturas morfológicas de mudas de eucalipto. Determinou-se os danos de C. cumulans com a utilização de 10 colônias de cupins. Cada colônia mantida em vasos de $30 \mathrm{~L}$ foi conectada a 4 mudas de eucalipto e outras 4 mudas não foram conectadas. As avaliações foram aos 15, 30, 60 e 90 dias após a implantação do experimento. Determinou-se a matéria seca da parte aérea e de raiz, altura, área foliar, bem como o comprimento, superfície, diâmetro e volume das raízes de eucalipto. $\mathrm{O}$ delineamento foi inteiramente casualizado em parcelas subdivididas, com dez repetições. Os resultados foram submetidos à análise de variância, sendo as médias comparadas pelo teste de Tukey $(\mathrm{P}<0,05)$. O ataque desses insetos, ao longo do tempo, ocasionou a redução do crescimento das plantas.

Palavras-chave: cupim, eucalipto, mudas, raiz

\section{DAMAGE OF Cornitermes cumulans (Kollar, 1832) (ISOPTERA: TERMITIDAE) ON Eucalyptus grandis $\mathrm{x}$ Eucalyptus urophylla SEEDLINGS}

\begin{abstract}
The objective of this study was to evaluate the damage of Cornitermes cumulans on morphological structures of eucalyptus seedlings. Termite damage was determined by using ten termite colonies. Each colony, maintained in $30 \mathrm{~L}$ pots, was connected to four eucalyptus seedlings and another four seedlings were not connected to the termite colonies. Evaluations were done at 15, 30,60, and 90 days after the establishment of this study. Epigeal and root dry matter, height, leaf area, as well as eucalyptus root length, surface, diameter, and volume were determined. The experimental design was completely randomized, with split plots and ten replicates. The results were submitted to analysis of variance and the means were compared by Tukey test $(\mathrm{P}<0.05)$. Attack by these insects as time goes by causes a reduction in plant growth.
\end{abstract}

Keywords: termite, eucalyptus, seedlings, root

\section{INTRODUÇÃO}

Em florestas naturais, as árvores geralmente são tolerantes ao ataque de cupins, mas em florestas plantadas há uma suscetibilidade ao ataque desses insetos desde o plantio até a colheita (WILCKEN,
2006). As alterações antrópicas, com o preparo das áreas para implementação de atividades agrícolas e florestais, podem tornar estes insetos pragas dos cultivos, devido aos desequilíbrios ecológicos gerados no ambiente (NÚÑEZ, et al., 2011). No Brasil há citações do ataque de cupins em 
cana-de-açúcar, milho, arroz, café, amendoim, eucalipto e pastagens (LEITÃOLIMA et al., 2012).

Os cupins do gênero Cornitermes constroem seus ninhos em forma de monte ou montículo e são comumente encontrados em área de pastagens, constituindo-se uma exceção quando encontrados em plantios homogêneos com espécies florestais (PERES FILHO et al., 2012). Junqueira \& Berti Filho (2000) relataram que estes cupins causaram a morte de 9 a $11 \%$ das mudas de eucalipto em uma estação experimental de silvicultura no estado de São Paulo. Seu dano ao sistema radicular é chamado de descorticamento do pião, que se constitui no anelamento da muda na região do colo, geralmente levando à morte (WILCKEN \& RAETANO, 1995).

Nas mudas que resistem aos danos causados pelos cupins pode haver formação de calos que darão origem a novo sistema radicular, logo acima daquele que foi destruído; ou será emitida brotação, para formação de nova parte aérea, caso tenha ocorrido o anelamento na região do colo. Essa resistência ou capacidade de tolerância ao ataque dos cupins não é satisfatória do ponto de vista econômico, pois as árvores terão sistema radicular superficial, sem sustentação adequada, com ocorrência de tombamentos, ou serão árvores suplantadas por espécies indesejáveis, devido ao atraso ocorrido no seu desenvolvimento inicial (WILCKEN \& RAETANO, 1995).

O estudo de raízes é trabalhoso, exigindo metodologia para coleta e procedimentos de análises extremamente criteriosos. Na literatura existem poucos trabalhos disponíveis que analisaram os danos causados por cupins a espécies florestais por meio da determinação de variáveis ligadas à estrutura radicular. Estas variáveis podem ser calculadas, com eficiência, por meio de sistema baseado no processamento e análise de imagens digitais, com o uso de "scanners" de mesa, o que tornou o estudo de raízes mais frequente.

As variáveis mais utilizadas para expressar o crescimento e a distribuição de raízes no perfil do solo, além da produção de matéria seca, são o comprimento, a superfície, o diâmetro e o volume radicular. Estas variáveis podem estar correlacionadas ou não entre si (GONÇALVES \& MELLO, 2000), caracterizando de forma distinta os danos causados pelo ataque de $C$. cumulans às raízes de eucalipto. $\mathrm{O}$ conhecimento da configuração do sistema radicular também é imprescindível como fonte de subsídios para explicar processos ecofisiológicos básicos (GONÇALVES \& MELLO, 2000), que irão repercutir, inevitavelmente, na parte áerea das plantas, havendo alterações na produção de matéria seca, área foliar, altura de plantas e outras características morfológicas.

O presente trabalho teve como objetivo avaliar os danos ao sistema radicular e parte aérea de mudas de eucalipto do clone do híbrido de Eucalyptus grandis $\mathrm{x}$ E. urophylla, recém transplantadas, expostas ao ataque de cupins da espécie Cornitermes cumulans ao longo do tempo.

\section{MATERIAL E MÉTODOS}

O trabalho foi realizado, em casa de vegetação, na Faculdade de Ciências Agronômicas/UNESP-Botucatu (SP), no setor de Defesa Fitossanitária do Departamento de Produção Vegetal, no ano de 2003.

O delineamento experimental foi de blocos casualizados em parcela subdividida, com 10 repetições. As parcelas foram constituídas por quatro períodos de avaliação dos danos de Cornitermes cumulans em mudas de eucalipto: 15, 30, 60 e 90 dias após a implantação do experimento. Já as subparcelas foram formadas por muda de eucalipto submetida ao ataque de $C$. cumulans ao lado de muda não exposta ao ataque. 
Para a formação dos blocos foram coletadas 10 colônias de $20 \mathrm{~cm}$ de diâmetro e $30 \mathrm{~cm}$ de altura de $C$. cumulans, localizadas em pastagens da FCA/UNESP. Para tal, efetuou-se escavação com enxada, em volta dos ninhos, retirando-os sem fragmentá-los. Cada colônia foi mantida em vasos plásticos de $30 \mathrm{~L}$, completados com solo, mantendo-se o conjunto sob sombreamento de $50 \%$. Em cada vaso, na sua borda superior, fez-se quatro furos equidistantes, para encaixe de mangueiras plásticas transparentes de $2 \mathrm{~cm}$ de diâmetro e $30 \mathrm{~cm}$ de comprimento, que ligavam as colônias até as mudas de eucalipto (Figura 1).

As mudas de eucalipto foram mantidas em tubos de PVC, com $30 \mathrm{~cm}$ de altura e 20 $\mathrm{cm}$ de diâmetro (Figura 1). Cada tubo de PVC foi preenchido com $10 \mathrm{~L}$ de Latossolo Vermelho Distrófico típico, textura média (EMBRAPA, 2006), com adubação de 100 ppm de $\mathrm{N}$ (uréia), $150 \mathrm{ppm}$ de $\mathrm{P}$ (superfosfato simples) e $150 \mathrm{ppm}$ de $\mathrm{K}$ $(\mathrm{KCl})$. A base ficou apoiada sobre pratos plásticos que continham pedra britada, facilitando a drenagem. Ressalta-se que em cada tubo de PVC, próximo a sua base, apresentava um furo para encaixe da mangueira de conexão ao vaso contendo a colônia de C. cumulans.

Foi utilizado o clone do híbrido Eucalyptus grandis x E. urophylla (VR 3748), no estádio de mudas em tubetes, prontas ao transplantio, fornecidas pelo viveiro da empresa Votorantim Celulose e Papel (VCP). Após o transplantio nos tubos de PVC foram necessários quinze dias de adaptação das mudas, para emissão de novas raízes, sendo então realizada a conexão com os vasos contendo as colônias de $C$. cumulans. Portanto, no total, 40 mudas foram expostas ao ataque de cupins e 40 mudas permaneceram sem conexão com as colônias (Figura 1).

As avaliações dos danos foram efetuadas a cada período de exposição pré- estabelecida das mudas de eucalipto ao ataque de $C$. cumulans. Assim, a primeira avaliação ocorreu aos 15 dias, desfazendo-se a conexão referente a esse tratamento (colônia / eucalipto), permanecendo as três outras conexões restantes (30, 60 e 90 dias). Em cada período atingido, para os tubos de PVC desconectados e suas respectivas subparcelas, determinou-se a altura das mudas (região do colo da planta até a inserção do último par de folhas). Em seguida, as plantas foram retiradas $\mathrm{e}$ separadas em partes aérea (folhas e ramos) e raiz. Utilizando "scanner" efetuou-se a digitalização das imagens das folhas, com processamento no software Image Tool v. 3.0 (WILCOX et al., 1997) e determinação da área foliar. Posteriormente, estas folhas juntamente com os ramos foram acondicionados em sacos de papel, postos em estufa, com ventilação forçada, a $60^{\circ} \mathrm{C}$ até peso constante, determinando-se a matéria seca (MS) da parte aérea.

Sobre peneira de malha fina as raízes foram lavadas em água corrente e, com auxílio de pinça, sofreram enxague final com água destilada. Após a lavagem das raízes, amostrou-se aproximadamente metade do volume radicular obtido em cada subparcela. Cada amostra foi colocada em frascos contendo álcool a $30 \%$, armazenadas sob refrigeração, com posterior determinação do comprimento radicular total $\left(\mathrm{cm} \mathrm{cm}^{-3}\right)$, superfície $\left(\mathrm{cm}^{2} \mathrm{~cm}^{-3}\right)$, diâmetro médio $(\mathrm{cm}$ $\left.\mathrm{cm}^{-3}\right)$ e volume total $\left(\mathrm{cm}^{3} \mathrm{~cm}^{-3}\right)$ das raízes, por meio da digitalização de imagem utilizando "scanner", desenvolvido para esse fim, acoplado a um computador dotado do software WinRhizo, cujo princípio segue a metodologia proposta por Tennant (1975). Após essas determinações, as amostras, juntamente com a alíquota das raízes não utilizadas nas avaliações supracitadas, foram secas em estufa e pesadas, determinando-se a MS das raízes, da mesma forma como efetuado para a parte aérea. 


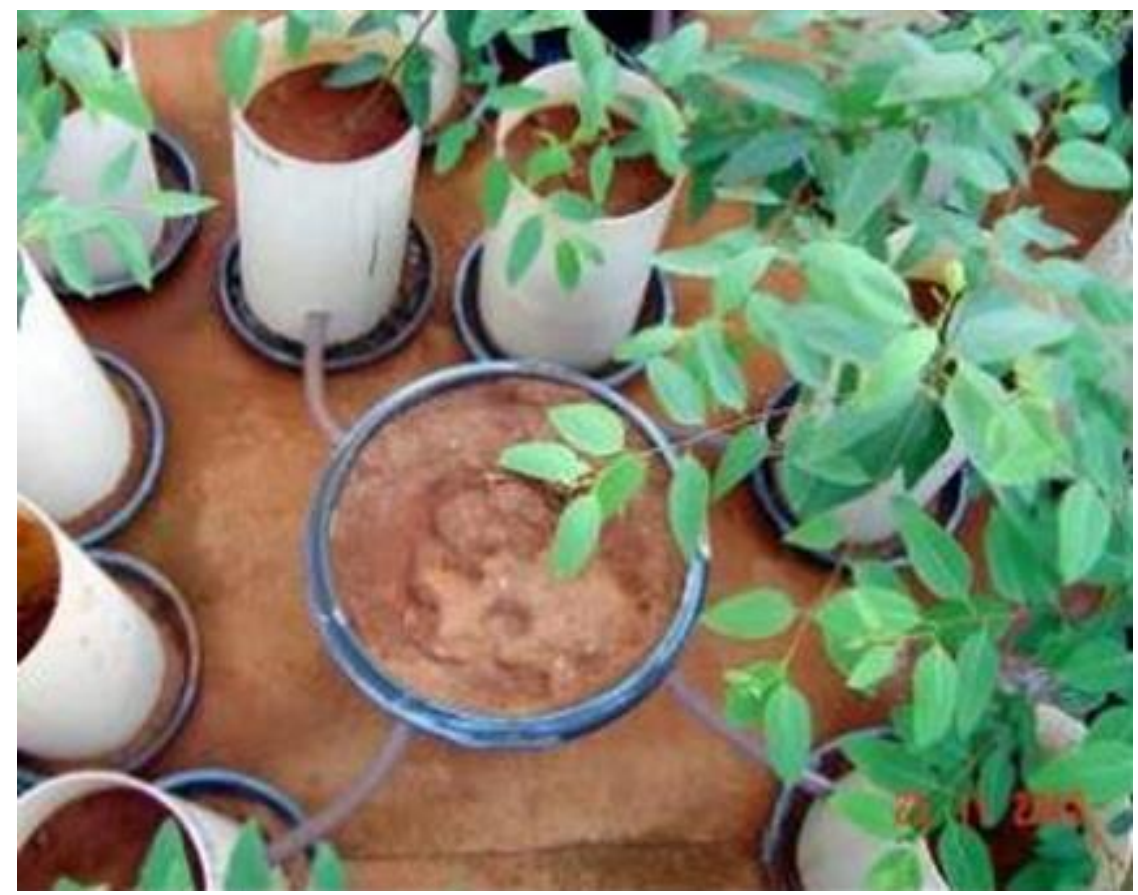

Figura 1. Vaso plástico contendo uma colônia inteira de Cornitermes cumulans conectado a quatro mudas de eucalipto (tubos de PVC), por meio de mangueiras plásticas, para determinação dos danos, com as respectivas mudas não expostas ao ataque (sem conexões com a colônia). Botucatu, SP, 2003.

As determinações foram submetidas a análises de variância, sendo as médias comparadas pelo Teste de Tukey $(\mathrm{P}<0,05)$. Apenas entre a MS de raiz com a MS da parte aérea, área foliar e altura, das mudas de eucalipto expostas ao ataque de cupins, realizou-se estudo de correlação simples (r). As análises estatísticas foram realizadas por meio do programa de computador ESTAT, conforme método descrito por Banzato \& Kronka (1989).

\section{RESULTADOS E DISCUSSÃO}

No dia seguinte a conexão dos vasos contendo as colônias de C. cumulans com os tubos de PVC contendo as mudas de eucalipto, foi possível observar intensa atividade dos cupins entre as duas estruturas. Inicialmente havendo a formação de galerias através das mangueiras plásticas transparentes de conexão, ou seja, as mesmas eram recobertas com solo, evitando- se a incidência direta de luz sobre os cupins. Posteriormente, antes das primeiras avaliações, já foi possível constatar a presença de cupins na superfície do solo dos tubos de PVC. Também, no momento da retirada das mudas dos vasos para separação das raízes, constatou-se a presença de operários de $C$. cumulans sobre as raízes de eucalipto.

Na Tabela 1, observa-se que para as variáveis MS de raiz, MS da parte aérea e área foliar, houve efeito significativo entre as interações período de dano $\mathrm{x}$ exposição ao ataque de cupins, sendo que para altura não se constatou essa interação, havendo o efeito isolado para os dois fatores. Portanto, de modo geral, a presença de operários de $C$. cumulans sobre as raízes de eucalipto pode causar danos diretos, consumindo o sistema radicular, e, consequentemente, danos indiretos, interferindo no crescimento das mudas de eucalipto, discordando de Macedo (1995), cuja afirmação foi a de que esses 
insetos raramente são encontrados atacando tecidos vivos da planta. Todavia, em florestas implantadas, os cupins podem ocasionar danos ao sistema radicular de eucalipto (SANTOS et. al., 2011). Em estudo realizado por Leitão-Lima et al. (2012), C. cumulans preferencialmente consumiram estruturas "in natura" de braquiária.

Com o desdobramento das interações (Tabela 2), verificou-se que houve o aumento na produção de MS de raiz, proporcional ao crescimento das mudas com o transcorrer do tempo, independentemente do ataque ou não de cupins às mudas de eucalipto. Entretanto, somente aos 90 dias de avaliação, o forrageamento dos cupins sobre as raízes de eucalipto influenciou significativamente na produção de MS de raiz, sendo menor em relação a muda não exposta ao ataque de cupins. Essa menor produção, verificada nas raízes atacadas por cupins, pode ser atribuída ao consumo das mesmas e senescência das raízes afetadas. A senescência de raízes finas pode ocorrer em função das condições estressantes, como variações estacionais e injúrias (GONÇALVES \& MELLO, 2000).

Assim como foi verificado para MS de raiz, a produção de MS da parte aérea e a área foliar, também apenas aos 90 dias, apresentaram redução significativa com o ataque de cupins (Tabela 2). Existe uma relação entre a produção de MS de raiz com a parte aérea, podendo os padrões de resposta de crescimento do sistema radicular interferirem no crescimento e desenvolvimento da parte aérea, diante da influência dos fatores ambientais (GONÇALVES \& MELLO, 2000).

Quanto a altura das plantas (Tabela 1), apesar da não interação entre os fatores e independente do período de dano, cuja elevação foi proporcional ao crescimento das mudas com o transcorrer do tempo, essa variável foi significativamente menor em função da exposição das mudas de eucalipto ao ataque de C. cumulans.

Tabela 1. Matéria seca (MS) de raiz, MS da parte aérea, área foliar e altura de mudas de eucalipto em função do período de dano e da exposição ao ataque de Cornitermes cumulans, Botucatu, SP, 2003.

\begin{tabular}{lcccc}
\hline Fatores & MS Raiz $(\mathrm{g})$ & MS Parte Aérea $(\mathrm{g})$ & Área Foliar $\left(\mathrm{cm}^{2}\right)$ & Altura $(\mathrm{cm})$ \\
\hline Período $(\mathrm{P})$ & & & & \\
15 dias & $9,41 \mathrm{~d}$ & $3,00 \mathrm{~d}$ & $373,16 \mathrm{~d}$ & $37,29 \mathrm{~d}$ \\
30 dias & $10,91 \mathrm{c}$ & $5,16 \mathrm{c}$ & $808,88 \mathrm{c}$ & $43,79 \mathrm{c}$ \\
60 dias & $19,97 \mathrm{~b}$ & $13,97 \mathrm{~b}$ & $1829,30 \mathrm{~b}$ & $56,81 \mathrm{~b}$ \\
90 dias & $40,35 \mathrm{a}$ & $34,84 \mathrm{a}$ & $4352,21 \mathrm{a}$ & $76,70 \mathrm{a}$ \\
Cupim $(\mathrm{C})$ & & & & \\
Sem ataque & $21,41 \mathrm{a}$ & $15,13 \mathrm{a}$ & $1836,28 \mathrm{a}$ & $55,72 \mathrm{~b}$ \\
Com ataque & $18,91 \mathrm{~b}$ & $13,35 \mathrm{~b}$ & $1845,55 \mathrm{a}$ & $51,58 \mathrm{a}$ \\
Valor de F & & & & \\
$(\mathrm{P})$ & $55,85 * *$ & $123 * *$ & $300,20 * *$ & $204,09 * *$ \\
(C) & $10,02 * *$ & $4,56 *$ & $0,01 \mathrm{~ns}$ & $8,41 * *$ \\
(P) $\mathrm{x}(\mathrm{C})$ & $5,71 * *$ & $6,10 * *$ & $3,71 *$ & $1,02 \mathrm{~ns}$ \\
CV & & & \\
$(\mathrm{P})$ & $42,27 \%$ & $41,00 \%$ & $24,98 \%$ & $10,14 \%$ \\
$(\mathrm{C})$ & $17,48 \%$ & $26,08 \%$ & $20,82 \%$ & $11,90 \%$ \\
\hline
\end{tabular}

Comparam-se letras na vertical. Médias seguidas por letras iguais e sem letras dentro de cada fator não diferem entre si pelo teste de Tukey a $(\mathrm{P}<0,05)$. * $\mathrm{e}^{* *}$ a 5 e $1 \%$ pelo teste $\mathrm{F}$, respectivamente, e ns- não significativo. 
Tabela 2. Desdobramento da interação período de dano x exposição ao ataque de Cornitermes cumulans, em mudas de eucalipto, para matéria seca (MS) de raiz, MS da parte aérea e área foliar, Botucatu, SP, 2003.

\begin{tabular}{|c|c|c|}
\hline \multirow{2}{*}{ Período } & \multicolumn{2}{|c|}{ Cupim } \\
\hline & Sem ataque & Com ataque \\
\hline & \multicolumn{2}{|c|}{ 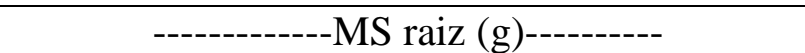 } \\
\hline 15 dias & $10,72 \mathrm{cA}$ & $8,11 \mathrm{cA}$ \\
\hline 30 dias & $10,72 \mathrm{cA}$ & $11,10 \mathrm{cA}$ \\
\hline 60 dias & $19,95 \mathrm{bA}$ & $19,98 \mathrm{bA}$ \\
\hline \multirow[t]{2}{*}{90 dias } & $44,24 \mathrm{aA}$ & $36,46 \mathrm{aB}$ \\
\hline & \multicolumn{2}{|c|}{-------------MS Parte aérea (g)---------- } \\
\hline 15 dias & $2,61 \mathrm{cA}$ & $3,39 \mathrm{cA}$ \\
\hline 30 dias & $4,72 \mathrm{cA}$ & $5,60 \mathrm{cA}$ \\
\hline 60 dias & $14,45 \mathrm{bA}$ & $13,48 \mathrm{bA}$ \\
\hline \multirow[t]{2}{*}{90 dias } & $38,74 \mathrm{aA}$ & $30,94 \mathrm{aB}$ \\
\hline & \multicolumn{2}{|c|}{-----------Área Foliar $\left(\mathrm{cm}^{2}\right)$-------- } \\
\hline 15 dias & $283,06 \mathrm{cA}$ & $463,27 \mathrm{cA}$ \\
\hline 30 dias & $772,15 \mathrm{cA}$ & $845,61 \mathrm{cA}$ \\
\hline 60 dias & $1701,09 \mathrm{bA}$ & $1957,68 \mathrm{bA}$ \\
\hline 90 dias & $4588,44 \mathrm{aA}$ & $4115,65 \mathrm{aB}$ \\
\hline
\end{tabular}

Médias seguidas das mesmas letras (minúsculas na coluna e maiúscula na linha) não diferem entre si pelo teste de Tukey $(\mathrm{P}<0,05)$

Com relação ao comprimento, superfície, diâmetro e volume radiculares houve efeito significativo na interação período de dano $\mathrm{x}$ exposição ao ataque de cupins (Tabela 3), desprezando-se então os efeitos isolados dos fatores.

Analisando os desdobramentos das interações (Tabela 4), só aos 60 dias o comprimento radicular foi menor com o ataque dos cupins. O comprimento de raízes finas de eucalipto é estreitamente relacionado à capacidade de adaptação às condições de estresse ambiental (MELLO et. al., 1998). Provavelmente, com o consumo do sistema radicular pelos cupins, a planta passou a emitir novas raízes, apresentando aos 90 dias valor de comprimento radicular semelhante às plantas não expostas ao ataque (Tabela 4). Ressalta-se também que o comprimento de raiz varia em função da época de coleta (WITSCHORECK et al.,
2003), bem como em função da espécie cultivada (GONÇALVES \& MELLO, 2000).

Com relação a superfície radicular, apenas na primeira avaliação (aos 15 dias), essa variável foi inferior no tratamento sem ataque. Entretanto, aos 60 e 90 dias, a superfície radicular apresentou valores menores com o ataque de cupins, havendo, entretanto, uma tendência de recuperação aos 90 dias, não suficiente para se igualar estatisticamente ao valor verificado neste mesmo período nas mudas sem a exposição ao ataque (Tabela 4$)$.

Com o crescimento das mudas de eucalipto sem e com o ataque de cupins, houve a diminuição do diâmetro radicular a partir dos 60 dias, provavelmente pela maior produção de raízes mais finas. Já na primeira avaliação (aos 15 dias), verificou-se diminuição substancial do diâmetro onde as raízes foram expostas ao ataque dos cupins, havendo aos 30 dias uma recuperação das mudas de eucalipto, apresentando resultado 
igual ao tratamento sem ataque. Contudo, aos 60 dias após a exposição ao ataque dos cupins, as mudas apresentaram diâmetro radicular menor do que as não submetidas ao ataque (Tabela 4). Esta tendência se manteve aos 90 dias, apesar da diferença não significativa. Possivelmente, o consumo das raízes pelos cupins proporcionou a redução observada no diâmetro das raízes de eucalipto, pelo fato desse estresse induzir a emissão de novas raízes, mais finas e, consequentemente, com menor diâmetro.

A determinação do volume radicular complementa as informações das outras variáveis radiculares analisadas, sendo que aos 90 dias foi possível constatar sua redução significativa para as mudas expostas ao ataque de $C$. cumulans (Tabela 4). De maneira geral, as variáveis superfície, diâmetro e volume apresentam alta correlação entre si (GONÇALVES \& MELLO, 2000).

O presente trabalho demostrou que o ataque de cupins nas raízes de mudas de eucalipto interferiu na estrutura morfológica do sistema radicular das plantas onde, de modo geral, constatou-se a redução das variáveis comprimento, superfície e diametro radiculares a partir de 60 dias após a exposição ao ataque de $C$. cumulans. Estas alterações na configuração do sistema radicular, em função do ataque de cupins, foram repercutidas aos 90 dias como verificado pela diminuição da MS de raiz, MS da parte aérea, área foliar e altura das mudas de eucalipto.

Tabela 3. Comprimento, superfície, diâmetro e volume radiculares de mudas de eucalipto em função do período de dano e da exposição ao ataque de Cornitermes cumulans. Botucatu, SP, 2003.

\begin{tabular}{|c|c|c|c|c|}
\hline Fatores & $\begin{array}{l}\text { Comprimento } \\
\left(\mathrm{cm} \mathrm{cm}^{-3}\right)\end{array}$ & $\begin{array}{l}\text { Superfície } \\
\left(\mathrm{cm}^{2} \mathrm{~cm}^{-3}\right)\end{array}$ & $\begin{array}{l}\text { Diâmetro } \\
\left(\mathrm{cm} \mathrm{cm}^{-3}\right)\end{array}$ & $\begin{array}{c}\text { Volume } \\
\left(\mathrm{cm}^{3} \mathrm{~cm}^{-3}\right)\end{array}$ \\
\hline \multicolumn{5}{|l|}{ Período (P) } \\
\hline 15 dias & 114,93 & 38,31 & 0,17 & 3,11 \\
\hline 30 dias & 159,25 & 77,47 & 0,35 & 3,15 \\
\hline 60 dias & 189,04 & 47,13 & 0,06 & 0,96 \\
\hline 90 dias & 223,95 & 69,94 & 0,20 & 1,87 \\
\hline \multicolumn{5}{|l|}{ Cupim (C) } \\
\hline Sem ataque & $188,83 \mathrm{a}$ & $57,20 \mathrm{a}$ & $0,25 \mathrm{a}$ & $2,40 \mathrm{a}$ \\
\hline Com ataque & $154,76 \mathrm{~b}$ & $59,22 \mathrm{a}$ & $0,15 \mathrm{~b}$ & $2,15 \mathrm{~b}$ \\
\hline \multicolumn{5}{|l|}{ Valor de F } \\
\hline (P) & $14,51 * *$ & $24,77 * *$ & $58,56 * *$ & $69,09 * *$ \\
\hline (C) & $7,97 * *$ & $0,24 \mathrm{~ns}$ & $12,63 * *$ & $13,53 * *$ \\
\hline$(\mathrm{P}) \times(\mathrm{C})$ & $3,36 *$ & $18,92 * *$ & $106,53 * *$ & $29,94 * *$ \\
\hline \multicolumn{5}{|l|}{$\mathrm{CV}(\%)$} \\
\hline (P) & 31,59 & 28,56 & 56,46 & 36,59 \\
\hline (C) & 31,41 & 31,49 & 56,02 & 31,41 \\
\hline
\end{tabular}

Comparam-se letras na vertical. Médias seguidas por letras iguais e sem letras dentro de cada fator não diferem entre si pelo teste de Tukey a $(\mathrm{P}<0,05)$. $\mathrm{e}^{* *}$ a 5 e $1 \%$ pelo teste $\mathrm{F}$, respectivamente, e ns- não significativo. 
Tabela 4. Desdobramento da interação período de dano x exposição ao ataque de Cornitermes cumulans, em mudas de eucalipto, para comprimento, superfície, diâmetros e volume radiculares. Botucatu, SP, 2003.

\begin{tabular}{|c|c|c|}
\hline \multirow{2}{*}{ Período } & \multicolumn{2}{|c|}{ Cupim } \\
\hline & Sem ataque & Com ataque \\
\hline \multicolumn{3}{|c|}{----------- Comprimento $\left(\mathrm{cm} \mathrm{cm}^{-3}\right)$--------- } \\
\hline 15 dias & $120,63 \mathrm{bA}$ & $109,22 \mathrm{bA}$ \\
\hline 30 dias & $158,96 \mathrm{bA}$ & $159,55 \mathrm{abA}$ \\
\hline 60 dias & $238,15 \mathrm{aA}$ & $139,93 \mathrm{bB}$ \\
\hline 90 dias & $237,57 \mathrm{aA}$ & $210,33 \mathrm{aA}$ \\
\hline \multicolumn{3}{|c|}{----- Superfície $\left(\mathrm{cm}^{2} \mathrm{~cm}^{-3}\right)-$} \\
\hline 15 dias & $12,06 \mathrm{cB}$ & $64,56 \mathrm{aA}$ \\
\hline 30 dias & $76,64 \mathrm{abA}$ & $78,30 \mathrm{aA}$ \\
\hline 60 dias & $59,75 \mathrm{bA}$ & $34,52 \mathrm{bB}$ \\
\hline 90 dias & $80,38 \mathrm{aA}$ & $59,51 \mathrm{aB}$ \\
\hline \multicolumn{3}{|c|}{---- Diâmetro $\left(\mathrm{cm} \mathrm{cm}^{-3}\right)$------- } \\
\hline 15 dias & $0,35 \mathrm{aA}$ & $0,04 \mathrm{bB}$ \\
\hline 30 dias & $0,45 \mathrm{aA}$ & $0,48 \mathrm{aA}$ \\
\hline 60 dias & $0,12 \mathrm{bA}$ & $0,06 \mathrm{bB}$ \\
\hline 90 dias & $0,06 \mathrm{bA}$ & $0,02 \mathrm{bA}$ \\
\hline \multicolumn{3}{|c|}{ - Volume $\left(\mathrm{cm}^{3} \mathrm{~cm}^{-3}\right)$} \\
\hline 15 dias & $2,99 \mathrm{aA}$ & $3,23 \mathrm{bA}$ \\
\hline 30 dias & $3,03 \mathrm{aB}$ & $3,26 \mathrm{aA}$ \\
\hline 60 dias & $1,24 \mathrm{bA}$ & $0,68 \mathrm{cA}$ \\
\hline 90 dias & $2,32 \mathrm{abA}$ & $1,41 \mathrm{cB}$ \\
\hline
\end{tabular}

As relações entre o sistema radicular e a parte aérea existem, onde a estabilidade do crescimento da parte aérea acompanha a taxa de crescimento radicular (GONÇALVES \& MELLO, 2000). Este fato foi confirmado por meio do estudo de correlação simples (r) feito entre a MS de raiz e as demais variáveis ligadas a parte aérea analisadas no presente trabalho, onde as correlações foram positivas, acima de 0,90 e significativa a $1 \%$ $(* *)$. O coeficiente de correlação $(r)$ entre a MS de raiz e da parte aérea das mudas de eucalipto atacadas por C. cumulans foi igual a $0,95^{* *}$. Já a MS de raiz e área foliar apresentaram correlação de $0,96 * *$ com ataque de cupins. A altura das mudas atacadas pelos cupins apresentou correlação com a MS das raízes de $0,93^{* *}$.
As mudas de eucalipto talvez desenvolvam mecanismos de adaptação aos ataques de $C$. cumulans, tentando compensar os danos causados, para uma possível retomada do crescimento das plantas, pois não houve mortalidade das mudas atacadas no presente experimento. Este fato pode ser inerente às características específicas do clone utilizado, que compensaria os danos iniciais. Além disso, as mudas foram regularmente irrigadas, evitando-se o estresse hídrico, o qual é passível de ocorrer no campo, condição essa de maior relevância à mortalidade de mudas. Deve-se considerar que no campo pode haver outras espécies de cupins que sejam mais agressivas que $C$. cumulans, causando mais danos em menor tempo, pois casos de mortes provocados por 
Syntermes são relativamente frequentes. De acordo com Valério (2005), os Syntermes spp., são diferentes das demais espécies que forrageiam folhas mortas. Este gênero forrageia cortando folhas verdes, lembrando formigas cortadeiras.

Os resultados apresentados devem ter implicação direta nas avaliações de controle de qualidade feitas nas áreas de plantios de eucalipto, pois atualmente os danos somente são considerados quando ocorre a morte da muda. A presença de $C$. cumulans, apesar de não ter chegado a provocar a mortalidade das mudas do presente experimento, teve nítida atuação sobre a redução e atraso do crescimento das plantas de eucalipto, podendo futuramente afetar a produtividade econômica. $\mathrm{O}$ monitoramento das infestações de cupins praga do eucalipto não é só importante para racionalizar o uso de cupinicidas (WILCKEN et. al., 2002), mas também para definir as áreas de risco, onde o controle pode manter o crescimento adequado das mudas até a colheita.

\section{CONCLUSÃO}

Os cupins da espécie Cornitermes cumulans causam redução e atraso no crescimento radicular e na parte aérea de mudas de eucalipto recém transplantadas.

\section{AGRADECIMENTOS}

À CAPES pela concessão da Bolsa de Doutorado e à empresa Votorantim Celulose e Papel S/A pelo fornecimento das mudas de eucalipto.

\section{REFERÊNCIAS BIBLIOGRÁFICAS}

EMBRAPA - Empresa Brasileira de Pesquisa Agropecuária. 2006. Sistema Brasileiro de Classificação de Solos. 2 ed. Rio de Janeiro: Embrapa Solos. 306 p.
BANZATO, D.A.; KRONKA, S.N. 1989. Experimentação agrícola. Jaboticabal: Funep, 247 p.

GONÇALVES, J.L.M.; MELLO, S.L.M. 2000. O sistema radicular das árvores. In: GONÇALVES, J.L.M.; BENEDETTI, V. (Eds.) Nutrição e fertilização florestal. Piracicaba: Instituto de Pesquisas e Estudos Florestais, p. 221-69.

JUNQUEIRA, L. K. ; BERTI FILHO, E. 2000. Termites (Insecta: Isoptera) in plantings of Eucalyptus spp. (Myrtaceae) in Anhembi, state of São Paulo, Brazil. Acta Biologica Leopoldensia, São Leopoldo, RS, v. 22, n. 2, p. 205-211.

LEITÃO-LIMA, P. da S.; LIMA, E. do V.; CUTRIM, D.O.; PINHEIRO, D.P. 2012. Preferência de Cornitermes cumulans (Kollar, 1832) (Isoptera: Termitidae) a diferentes estruturas morfológicas de Brachiaria brizantha em pastagens degradadas na Amazônia. Revista de Agricultura, Piracicaba, SP, v.87, n.2, p. 102-112.

MACEDO, N. 1995. Atualização no controle de cupins subterrâneos em cana-deaçúcar. In: BERTI FILHO, E., FONTES, L.R. (Ed.) Aspectos atuais da biologia e controle de cupins. Piracicaba: FEALQ, p. 121-126.

MELLO, S. L. M.; GONÇALVES, J.L.M.; OLIVEIRA, L.E.G. 1998. Características do sistema radicular em povoamentos de eucaliptos propagados por sementes e estacas. Scientia Forestalis, v.54, p. 1626.

NÚÑEZ, B. N. C.; LIMA, M. S. C. S.; MENEZES, E. B.; PEDERASSI, J. 2011. Ocupação de ninhos de cupins epígeos e arbóreos em fragmento de caatinga hipoxerófila em Bom Jesus-PI. Comunicata Scientiae. Teresina. v.2, n.3, p. 164-169.

PERES FILHO, O.; SOUZA, J.C., SOUZA, M.D.; DORVAL, A. 2012. Distribuição espacial de cupinzeiros de Cornitermes snyderi (Isoptera: Termitidae) e sua 
associação com teca. Pesquisa Florestal Brasileira, Colombo, v.32, n. 70. p. 5966.

SANTOS, A.; ZANETTI, R.; BUFALINO, L; SILVA, W.L.P. 2011. Sobrevivência de operários do cupim-de-montículo Cornitermes cumulans (Kollar, 1832) (Isoptera Termitidae) alimentados com diferentes dietas artificiais. Arquivos do Instituto Biológico, São Paulo, v.8, n.1, p. 151-154.

TENNANT, D.A. 1975. Test of a modified line intersect method of estimating root length: Journal of Ecology, London, v.63, p. 995-1001.

VALÉRIO, J.R. Insetos pragas de gramíneas forrageiras: Identificação e controle. In: Pedreira, C.G.S. et al. (Ed.) Teoria e prática da produção animal em pastagens. Anais do $22^{\circ}$ Simpósio sobre manejo de pastagem, FEALQ, Piracicaba, SP, 2005.

WILCKEN, C.F. 2006. Controle biológico de pragas florestais. Revista Opiniões Celulose e Papel, Ribeirão Preto, p. 38 38.

WILCKEN, C.F.; RAETANO, C.G. 1995. Controle de cupins em florestas. In: BERTI FILHO, E. \& FONTES, L.R. (Eds.) Alguns aspectos atuais da biologia e controle de cupins. p. 141-154.

WILCKEN C.F.; RAETANO, C.G.; FORTI, L.C. 2002. Termite pests in Eucalyptus forest of Brazil. Sociobiology. v.40, n.1, p. 179-190.

WILCOX, D.; DOVE, B.; McDAVID, D.; GREER, D. 1997. UTHSCSA Image Tool Version 2.0. University of Texas, Health Science Center, p. 51.

WITSCHORECK, R.; SCHUMACHER, M.V.; CALDEIRA, V.W. 2003. Estimativa da biomassa e do comprimento de raízes finas em Eucalyptus urophylla ST. Blake no município de Santa Maria-RS. Revista Árvore, v.27, n.2, p. 177-183, 2003.
Recebido em: 20/06/2013 Aceito para publicação em: 06/09/2013 